for her specialist knowledge - was suspected of being a double agent. A counter-intelligence officer, reviewing her file, decided that she had passed the test: "This woman is gonna be the next Director of Intelligence for DIA. She's just fabulous." She was arrested in 2001.

She was not even a particularly accomplished spy, Gladwell notes. Her secret codes from Havana were in her purse, her shortwave radio in a shoebox in her cupboard. "The issue with spies is not that there is something brilliant about them," Gladwell writes. "It is that there is something wrong with us." Further crisply told case studies amplify his argument, from a bleak account of 'enhanced interrogation' techniques used to extract dubious confessions from al-Qaeda operative Khalid Sheikh Mohammed, to readings of coded facial expression in the US television series Friends.

In addition, Gladwell discusses a bias towards default-to-truth. This is beautifully explicated in the case of the more than US\$50-billion fraud by financier Bernard Madoff, made public in 2008. (Madoff is currently serving a 150 -year sentence.)
People repressed suspicions about the schemer because they trusted the regulatory system. Few believed fund manager Harry Markopolos, who identified the fraud around 2000 and repeatedly reported it to the Securities and Exchange Commission. However, as Gladwell points out, if we had too low a trust threshold, we'd never commit to anything and would forever be suspicious. But that is just part of Gladwell's story.

He explores, for instance, the sociological concept of coupling: how aspects of place can affect the outcome of close encounters and related decisions. A 1988 study, for instance, showed how the removal of carbon monoxide from the public gas supply in England and Wales led to a steep decline in the number of people taking their own lives between 1963 and 1975 (R. V. Clarke and P. Mayhew Crime Justice 10, 79-116; 1988). And US criminologists have found that for better overall crime prevention, police patrols should focus on urban crime hotspots (D. Weisburd Criminol. Public Policy 17, 5-25; 2018).

These findings, Gladwell asserts, have relevance for the tragic outcome of the incident in Texas. He does note that African American drivers are more likely to be stopped than white ones. But he persuades us to reconsider the episode as a misunderstanding between an over-zealous traffic cop in the wrong place and a motorist who should never have been stopped. It remains hard, however, to imagine that it would have ended so badly had Bland been white. Ultimately, Gladwell delivers analysis, but not much in the way of answers.

In close encounters with those we don't know, Gladwell recommends "restraint and humility". His examples of what happens without that have immediate and obvious political resonance. Perhaps wisely, he declines to make the connection. "Those occasions when our trusting nature is violated are tragic," Gladwell writes. "But the alternative - to abandon trust as a defense against predation and deception - is worse." -

Tim Radford is a former science editor of The Guardian, and author of The Consolations of Physics. e-mail:radford.tim@gmail.com

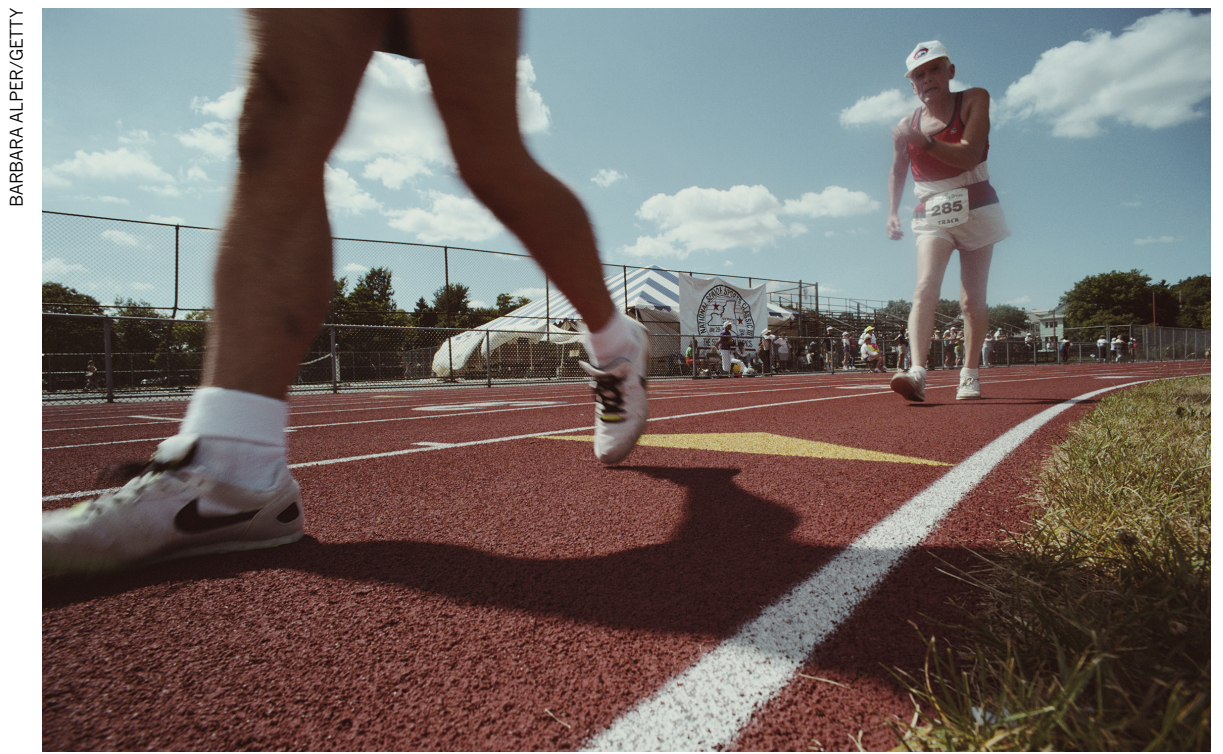

Staying active into old age can extend health.

\title{
GERONTOLOEY
}

\section{The enlightenment of age}

\section{Toren Finkel lauds two books outlining very different ways of boosting 'healthspan' - through drugs or care.}

$\mathrm{T}$ This year, people over 65 began to outnumber those under 5 for the first time in history. Like climate change, the ageing of humanity is indisputable. Yet the implications of that, and remedies for it, are subject to considerable debate. Now, two books with very different perspectives seek to address how to prepare for this 'grey tsunami'.

Lifespan, by geneticist David Sinclair and journalist Matthew LaPlante, provides a vision of a not-too-distant future in which living beyond 120 will be commonplace. Physician Louise Aronson's Elderhood focuses, by contrast, on the often bewildering and sometimes dehumanizing landscape of current geriatric care. Both books wrestle with the complexities of the coming demographic shift. Countries such as the United States - already devoting more than onethird of its health-care dollars to people over 65 - will have to come to terms with an iller, older population. But their solutions are distinct. For Sinclair and LaPlante, the answer lies in understanding and leveraging why we age; for Aronson, in re-evaluating and reorienting how we view and treat older people.

\section{AGE AS DISEASE}

Lifespan is entertaining and fast-paced - a whirlwind tour of the recent past and a near future that will see 90 become the new 70 . In a succession of colourfully titled chapters ('The demented pianist', 'A better pill to swallow'), Sinclair and LaPlante weave a masterful narrative of how we arrived at this crucial inflection point. Among the historical figures evoked are a sixteenth-century Venetian proponent of caloric restriction, Luigi Cornaro, and the twentieth-century 'father of information theory', Claude Shannon.

The authors detail how we might alter the trajectory of human ageing by extrapolating from Sinclair's own research on key signalling molecules such as $\mathrm{NAD}^{+}$and the proteins called sirtuins, which alter the lifespans of yeast, certain worms and mice. They predict the emergence of drugs that will modulate these and other molecules known to be $>$ 
> involved in longevity pathways, or destroy harmful senescent cells that accumulate as we age and help to fuel disease. Sinclair and LaPlante claim that some of these drugs might already be here. The effects of the widely prescribed diabetes drug metformin and the immune modulator rapamycin, for instance, seem to mimic beneficial strategies - the equivalent of (respectively) exercising more and eating less, in pill form.

Defining ageing as a disease is central to their approach. If we treat age medically, as we do heart disease or cancer, they argue, innovative therapies will emerge more rapidly. That mirrors the increasingly popular 'geroscience hypothesis', which posits that therapies targeting the fundamental biology of ageing will help to slow or prevent chronic diseases that plague older people, such as type 2 diabetes and dementia. Sinclair's argument, based on decades in the lab, is that there is no immutable biological tenet that limits how long, or how well, we can live.

Sinclair and LaPlante examine the economics of extending lives on a crowded, resource-limited planet, and the ethics of tinkering with the supposed natural order. But they also speculate on some inadvertent, potentially positive effects. Knowing you were going to meet your great-greatgrandchildren, for instance, might make you a more accountable steward of the present. If many generations lived and worked together, we might all become more empathetic - as Sinclair puts it, "more human". At a time of political, economic and environmental uncertainty, that could be ever more important.

If Lifespan is a lively sprint into the future of ageing, Elderhood is a contemplative walk in its here and now. Since the early 1990s, Aronson has worked as a geriatrician at the University of California, San Francisco. Her exquisitely written book mixes vignettes about her patients (remarkably, she still makes house calls) with lessons learnt from caring for her elderly parents and insights
Lifespan: Why We Age — and Why We Don't Have To

DAVID A. SINCLAIR AND MATTHEW D. LAPLANTE

Atria (2019)

Elderhood: Redefining Ageing, Transforming Medicine, Reimagining Life

LOUISEARONSON

Bloomsbury (2019)

from her own experience of ageing.

Many of her stories reveal cracks in the US health-care system. We learn, for instance, about Neeta, a frail patient with mild dementia who breaks her hip. After surgery, Neeta is transferred to a less-than-stellar care home where she becomes agitated, is sedated, develops bedsores and spirals into hospice care. We also learn of Aronson's personal frustrations. In one instance, when physicians in a busy accident and emergency department were too distracted, she had to perform a rectal examination on her own father to demonstrate that he was bleeding internally.

\section{ESSENTIAL STAGE}

Meshed with these very human tales are a wealth of social, cultural and historical perspectives. At the start of the book, Aronson tells of an encounter with Guy Micco, a physician teaching at the University of California, Berkeley. Micco asked a class to write down associations with the word 'old': concepts such as weak and frail predominated. The word 'elder', by contrast, elicited terms including respect, experience and knowledge. To Aronson, part of the problem is that we adhere to a utilitarian, late-nineteenth-century concept of the body as a machine. Viewed through that industrial lens, being 'old' is no longer the apex of life experience. It is a loss of function and, by extension, of intrinsic worth.

Aronson sees life as a three-act drama: childhood, adulthood and elderhood, the latter subdivided into senior, old, elderly and aged. Each act builds on the one before, and is essential. Aronson notes that emphasizing only the vicissitudes of elderhood is like saying that youth is defined by acne. In fact, in old age we might know ourselves better than ever and obtain more overall life satisfaction. Aronson conceives of anti-ageing not as Sinclair and LaPlante see it - as a bid to medically 'cure' the condition — but as battling the many "discriminatory beliefs and policies" affecting the elderly. In her view, the very idea of 'curing' ageing is ageist; such a concept is not invoked for any other life stage.

Indeed, in Aronson's eyes, the worst offender might be the medical system itself. She sees it as failing both patient and physician. It lacks nuance on subtle but important differences in life phases, and focuses on "diseases and organs rather than people and lives". For instance, she notes that many over-the-counter medicines are not tested on older people, adding risk to prescribing them. She advocates a new paradigm: a re-balancing act in which technology has a role but the focus returns to care. Unlike the high-tech, algorithmic march of modern medicine, her idea of truly 'personalized medicine' incorporates the patient's past experiences and current expectations. This integrative, humanistic model of geriatrics is rare. One can only hope its practices are adopted swiftly.

What are we to conclude? Is ageing a disease that can be eradicated by science, or the natural third act of life, threatened by over-medicalization? Viewpoints will undoubtedly be as variable as experience and temperament. There might be some wisdom in simply following an adage attributed to seventeeth-century philosopher Francis Bacon: "old age is always 15 years older than I am". .

Toren Finkel holds the Beckwith Chair in Translational Medicine and is director of the Aging Institute at the University of Pittsburgh and the University of Pittsburgh Medical Center in Pennsylvania. e-mail:finkelt@pitt.edu

\section{India on Mars: the film}

\section{Subhra Priyadarshini lauds a movie on the country's first interplanetary mission.}

$\mathrm{I}$ n 2013, India reached for Mars. Its first interplanetary mission, dubbed Mangalyaan (officially the Mars Orbiter Mission, or MOM), launched a probe carrying five instruments to study aspects of the red planet, from its mineral composition to potential signs of past life. Now, a fictional treatment on film by first-time director Jagan Shakti celebrates the scientists who got
Mission Mangal

DIRECTOR: JAGAN SHAKTI

Cape of Good Films/ Hope/Fox Star Studios (2019)

months from approval th lift off when Mars would be closest to Earth It is very much a homage to the Indian Space
Research Organisation (ISRO) and the country's technological prowess, and as such stirs up national pride. But the film is also successful scientific storytelling, performed by a glittering cast.

Science communication can be notoriously tricky, treading a line between oversimplification of concepts and overuse of jargon. Mission Mangal avoids the latter, 